\title{
Indoor air quality and thermal comfort in elderly care centers
}

\author{
Ana Mendes ${ }^{a, *}$, Stefano Bonassi ${ }^{b}$ Lívia Aguiar $^{a}$, Cristiana Pereira ${ }^{a}$, \\ Paula Neves ${ }^{a}$, Susana Silva ${ }^{a}$, Diana Mendes ${ }^{a}$, Luís Guimarães ${ }^{a}$, \\ Rossana Moroni ${ }^{\mathrm{b}}$, João Paulo Teixeira ${ }^{\mathrm{a}, \mathrm{c}}$ \\ ${ }^{a}$ Environmental Health Department, Portuguese National Health Institute Doutor Ricardo Jorge, Rua Alexandre Herculano, 321, \\ 4000-055 Porto, Portugal \\ ${ }^{\mathrm{b}}$ Unit of Clinical and Molecular Epidemiology, IRCCS San Raffaele Pisana, Via di Val Cannuta, 247, 00166 Rome, Italy \\ ${ }^{\mathrm{c}}$ Institute of Public Health (ISPUP), Porto University, Rua das Taipas, 135, 4050-600 Porto, Portugal
}

\section{A R T I C L E I N F O}

\section{Article history:}

Received 2 December 2013

Revised 11 July 2014

Accepted 15 July 2014

Keywords:

Indoor air quality

Thermal comfort

Building assessment

Elderly care centers

Older people

\begin{abstract}
A B S T R A C T
This study explored environmental variables and buildings characteristics in 22 elderly care centers (ECCs) in Portugal. Indoor environmental parameters were measured twice for a total of 141 sampling sites. Each site was assessed for $\mathrm{PM}_{10}, \mathrm{PM}_{2.5}$, total volatile organic compounds (TVOC), formaldehyde, $\mathrm{CO}, \mathrm{CO}_{2}$, total bacteria and fungi. Thermal comfort (TC) parameters were measured according to ISO 7730:2005 and a building characterization was performed. The overall $\mathrm{PM}_{2.5}$ mean concentration of the $22 \mathrm{ECC}$ was above international reference levels in summer and winter seasons. TVOC, bacteria, $\mathrm{CO}$ and $\mathrm{CO}_{2}$ showed significantly higher indoor levels compared to outdoor, in both seasons. Indoor $\mathrm{PM}_{10}$, TVOC, bacteria and $\mathrm{CO}_{2}$ present significant differences between seasons. TVOC, bacteria and $\mathrm{CO}_{2}$ show significant variation between ECC rooms and $4 \%$ of fungi samples were positive for pathogenic Aspergillus species. The winter predicted mean vote (PMV) index showed a 'slightly cool' thermal sensation scale which may potentiate respiratory tract infections. The predicted percent of dissatisfied people (PPD) and PMV indices show significant differences by season. The building variables 'Insulation', 'Heating Ventilation' and 'Windows frames' were significantly associated to chemical, biological and TC parameters. 'Bacteria', 'Fungi', 'Temperature', Relative Humidity', and 'PPD index' are the mostly affected by building characteristics. Insulating ceilings, walls, and
\end{abstract}

\footnotetext{
* Corresponding author. Tel.: +351964 780242 .

E-mail address: asestevao@gmail.com (A. Mendes).
} 
windows could improve winter season TC, providing health benefits to ECC residents.

(c) 2014 Elsevier B.V. All rights reserved.

\section{Introduction}

According to the United Nations estimates, the total number of people aged 65 years and older was 506 million in 2008 and is anticipated to double to 1.3 billion by 2040, accounting for the 14 percent of total global population. By 2050, Europe will continue to be the world's oldest region with its elder population increasing more than fivefold from 40 million to 219 million (Bentayeb et al., 2013). These demographic changes result in new patterns of morbidity and mortality, such as the increasing number of patients simultaneously affected by different chronic diseases. Healthcare organizations throughout the world have an increasing concern about how to cope with a quickly aging population (Caley and Sidhu, 2011). This trend explains the increasing demand of long-term care services (Damiani et al., 2009) such as elderly care centers (ECCs). Furthermore, considering that persons who are 65 years or older often spend a considerable portion of their lives indoors it is clear that the possibility that adverse indoor climate can influence their health status cannot be ignored.

As levels of outdoor air pollution have been reported to decrease in many areas, indoor air quality (IAQ) has increasingly gained importance. It is estimated that in developed countries people spend $80 \%$ to $90 \%$ of their day indoor (Kembel et al., 2012), and this figure is likely to be higher in elderly. This prolonged exposure to indoor air pollutants of this age-group - even at low concentrations may induce health damage more likely than occasional exposure to outdoor pollutants (Corsi et al., 2012). In addition to IAQ also thermal comfort (TC) is a key factor that might affect comfort, health, and occupants' performance (Mendes et al., 2013). Thermal comfort is influenced by a range of environmental and individual factors, both objective and subjective, including air temperature, the temperature of the surrounding surfaces, the air movement, the relative humidity, and the rate of air exchange (ventilation) (Ormandy and Ezratty, 2012).

Living in a ECC may induce exposure to chemical compounds through their release from building materials, household furnishings, and a wide range of consumer products (Spengler and Adamkiewicz, 2009). Furthermore, indoor habitat has been found to harbor microbial taxa not commonly found outdoors, and it has been reported that air temperature and relative humidity, as well as the source of ventilation air and occupant density, can influence the abundance and transmission of some pathogenic microbes (Kembel et al., 2012). Inadequate air-conditioning systems, low ventilation rate, and overcrowding can increase these risks (Wan et al., 2011).

Fine particulate matter, with diameter $2.5 \mu \mathrm{m}$ or less $\left(\mathrm{PM}_{2.5}\right)$, can penetrate deeply into lung tissue and be associated with reduced lung function in children and adults, lung inflammation, respiratory symptoms, adverse cardiovascular effects, and increased prevalence of chronic obstructive pulmonary disease (COPD) (Wang et al., 2006). PM $_{2.5}$ exposure can also cause oxidative stress to human DNA (Sørensen et al., 2003). The quality of indoor climate is affected equally by the building equipment and operation and maintenance. However, critical conditions may originate from the buildings themselves, or actions of the occupants or operation and maintenance of the buildings (Seppänen et al., 2004). Although housing standard is important for indoor climate, knowledge on different aspects of individual daily behavior patterns, especially those related to thermoregulatory behavior and home heating habits, is a critical piece of information (Bokenes et al., 2011). In general elderly energy expenditure decreases with increasing age because of a reduction in basal metabolic rate and also because elderly tend to be less active (Antunes et al., 2005). Due to this mechanism, elder population has an average comfort zone/thermal neutrality (where the body is able to maintain a balance between heat production and heat loss) higher than the general population $\left(25^{\circ} \mathrm{C}\right.$ in summer and $23^{\circ} \mathrm{C}$ in winter) (Hwang and Chen, 2010; Schellen et al., 2010), and is more sensitive to respiratory infections in the winter (Ormandy and Ezratty, 2012; Mourtzoukou and Falagas, 2007) and heat-related mortality 
during the summer heat waves (Kovats and Hajat, 2008). Poor thermal environment can also aggravate the impact of air pollutants on occupant's health.

However, Indoor environmental conditions vary in space and time, and health risk may depend on factors such as the time pattern of exposure, as well as on individual features such as age, gender, genetic heritage, and underlying state of health. More studies on indoor pollutants and health in the elderly are needed, with an improved exposure assessment, evaluation of short-term and longterm outcomes, identification of susceptible subgroups (Simoni et al., 2003).

This paper presents results which have been produced within the GERIA ongoing project 'Geriatric study in Portugal on Health Effects of Air Quality in Elderly Care Centers', by measuring and characterizing IAQ and TC in 22 ECCs out of 58 (with an overall number of 1355 residents), in Porto, Portugal. Aim of the study was to evaluate (1) the indoor air quality and thermal comfort in a representative sample of ECCs in Porto as compared with national and international standards, (2) to study the variability among different spaces within single ECCs, and (3) how buildings characteristics may affect the extent of indoor air pollution or thermal regulation.

\section{Material and methods}

All ECCs located within the Porto urban area and included in the 'Portuguese Social Charter' where invited to participate in our study. Out of a total of 58 ECCs located in Porto urban area, 38\% $(n=22)$ accepted to participate in this study. Data were collected for each ECC in two seasons (i.e. summer and winter), and the following parameters were measured: (i) building and ventilation characteristics; (ii) environmental, chemical, biological and thermal comfort parameters; (iii) index of thermal comfort, i.e., predicted mean vote (PMV) which predicts the mean response of a larger group of people according to the seven point thermal sensation scale (ISO 7730:2005), and predicted percent of dissatisfied people (PPD) as a quantitative measure of the TC of a group of people at a particular thermal environment.

The city of Porto (41N11.8W36) is located along the Douro river estuary in northern Portugal, featuring the Mediterranean climate (Köppen climate classification $=\mathrm{Csb}$ ) with moderate temperatures and rainy weather in the winter season, and milder summers due to the nearby presence of cold ocean currents that bring fog but prevent rain. The research team considered that all the ECCs included in the study were exposed to the same climate.

\subsection{Buildings walk-through survey}

The building characterization included the following information: type of building construction (concrete, masonry, etc.); thermal isolation of the building; characteristics of building envelope (type of windows and doors, presence of weather stripping, etc.); ventilation system (natural, mechanical, hybrid, etc.); types of indoor materials; use of gas burning appliances; evidence of dampness or mold; ventilation practices (opened windows). All ECCs were smoke-free.

\subsection{Indoor air monitoring and thermal comfort assessment}

IAQ parameters were measured twice, during winter and summer seasons, starting from November 2011 till August 2013, and included chemical parameters [carbon monoxide (CO), carbon dioxide $\left(\mathrm{CO}_{2}\right)$, formaldehyde, total volatile organic compounds (TVOC), particulate matter up to 10 and 2.5 micrometers in size $\left(\mathrm{PM}_{10}\right.$ and $\left.\mathrm{PM}_{2.5}\right)$ ], and biological contaminants (total bacteria and fungi). TC parameters were measured at the same time (following ISO 7730:2005) including the PMV and PPD indices, relative humidity $(\mathrm{RH})$, temperature and air velocity. The monitoring was performed in each ECC in the following spaces: dining rooms, drawing rooms, medical offices and bedrooms, including the bedridden subgroup. A total of 141 areas were evaluated. Ambient air samples were also collected for comparison to the indoor measurements. All active sampling and the associated analytical measurements were performed in replicate (in the same room) and duplicate (in the same sampling point). This work was performed by the Environmental Health Department of National Health 
Institute using methodologies accredited by NP EN ISO/IEC 17025:2005 "General requirements for the competence of testing and calibration laboratories".

\subsubsection{Sampling schedule and locations}

The monitoring phase included daytime air sampling (starting at $10 \mathrm{am}$ and continuing for at least $4 \mathrm{~h}$ to $8 \mathrm{~h}$ during normal activities) conducted discretely to minimize nuisance to normal resident's activities. Samplers were placed at a height of $0.6-1.5 \mathrm{~m}$ above the floor, approximately at the breathing zone level, and as close as possible to the center of the room. Sampling points were always located more than $1 \mathrm{mt}$. from walls, windows, doors or an active heating system.

\subsubsection{Suspended particle matter $\left(P M_{10} \& P M_{2.5}\right)$}

$\mathrm{PM}_{10}$ and $\mathrm{PM}_{2.5}$ samples were collected using polytetrafluoroethylene (PTFE) filters on SKC Personal Environmental Monitors (PEM), Gilian personal pumps, and a sample flow rate of $2.0 \mathrm{~L} \mathrm{~min}^{-1}$ following US Environmental Protection Agency (EPA) Method 10-A, 'Determination of Respirable Particulate Matter in Indoor Air Using Size Specific Impaction' (Winberry et al., 1990). Pumps were calibrated and checked prior and after each sample using a Gillian Gilibrator-2 Air Flow Calibrator. Before sampling, filters were stored in a desiccator for equilibration. At least one field blank per sampling event was used. Exposed and unexposed filters protected from dust and sunlight during transportation, and kept away from air in a closed filter holder. Each filter was weighed under controlled temperature $\left(20 \pm 1^{\circ} \mathrm{C}\right)$ and relative humidity $(50 \pm 5 \%)$ before and after sampling using an electronic microbalance (Sartorius M5P with $0.001 \mathrm{mg}$ of precision). Static charges were eliminated using a non-radioactive, ionizing air blower (EXAIR, Model No. 7907). Concentrations were calculated from the difference in filter weight and the sample air volume.

\subsubsection{TVOC and formaldehyde}

TVOC samples were collected by drawing air through a stainless steel sampling tube containing Tenax TA using a personal air sampling pump (SKC Pocket pump) at a flow rate of $0.05 \mathrm{~L} \mathrm{~min}^{-1}$ for a period of $45 \mathrm{~min}$. These pumps were calibrated and checked daily prior and after each sample using a Gilian Gilibrator-2 Air Flow Calibrator. Before sampling, each tube was conditioned at $250^{\circ} \mathrm{C}, 300^{\circ} \mathrm{C}$ and $330^{\circ} \mathrm{C}$ for $30 \mathrm{~min}$ consecutively in the helium carrier gas flow. Analysis of volatile organic compounds (VOCs) was performed by automatic thermal desorption coupled with capillary gas chromatography using a Perkin Elmer ATD 400 and AutoSystem GC fitted with flame ionization detector (FID) and an SE30 column, according to ISO 16000, part 6 (International Organization for Standardization, 2004), and an internal method following ECA Report 19 (European Commission Joint Research Centre Environment Institute, 1997). TVOC was quantified using the toluene response factor, and concentrations were calculated as the sum of identified and unidentified compounds eluting between hexane and hexadecane (included), expressed as toluene.

Formaldehyde was measured by active sampling using 2,4 dinitrophenylhydrazine-coated glass fiber filters in Millipore Swinnex-13 filter holders, personal pumps (SKC AirChek 2000), and a flow rate of $0.8 \mathrm{~L} \mathrm{~min}^{-1}$ (calibrated and checked daily prior and after each sampling with Gilian Gilibrator-2 Air Flow Calibrator). Concentrations were determined by high-performance liquid chromatography (HPLC) using the methods reported by Levin et al. (1996) and the National Institute for Occupational Safety and Health (NIOSH) 2016:2003 (National Institute for Occupational Safety and Health, 2003). Each analysis used certified reference standards as well as duplicate and recovery samples.

\subsubsection{Carbon dioxide and carbon monoxide}

$\mathrm{CO}_{2}$ and $\mathrm{CO}$ concentrations were determined using a portable IAQ monitor (GasData, model PAQ) during the occupied period. Short-term measurements (30 min average) were collected in each room. After the equipment stabilized, measurements were recorded continuously using PCLogger 32 V3.0 software.

\subsubsection{Bacteria and fungi}

Microorganism air sampling was conducted following NIOSH Method 0800 - Bioaerosol Sampling (Indoor Air) (National Institute for Occupational safety and Health (NIOSH), 1998) and ISO 1600018:2011 (International Organisation for Standardization, 2011), using a microbiological air sampler 
(Merck Air Sampler MAS-100), an air flow rate of $100 \mathrm{~L} \mathrm{~min}^{-1}$, and two agars, tryptic soy agar (TSA) for total bacteria and malt extract agar (MEA) for fungi. Both indoor and outdoor samples (250 L) were collected in duplicate and with one field blank, per culture medium, per day. To quantify fungi, samples were incubated at $25^{\circ} \mathrm{C}$. Identification of fungal colonies was based upon phenotypic characteristics and followed standard mycological procedures (International Organisation for Standardization, 2003). Bacteria were incubated at $37^{\circ} \mathrm{C}$. Results were expressed as colony-forming units per cubic meter of air $\left(\mathrm{CFU} / \mathrm{m}^{3}\right)$.

\subsubsection{Thermal comfort parameters}

ECCs rooms 'homogeneous' and steady-state environment were tested according ISO 7726:1998 (International Organisation for Standardisation, 1998) specifications with TSI 8386A-M-GB thermoanemometer. Moderate environments (class C - comfort standard) were considered. Objective physical data, including air temperature, relative humidity and air velocity were collected by Delta $\mathrm{Ohm}$ HD 32.1 - Data logger, placed at a height of $0.60 \mathrm{~m}$ above the floor (sitting - abdomen level). All monitoring data were collected as close as possible to the center of the room, with the sampling points no closer than $1 \mathrm{~m}$ to a wall, a window, a door or an active heating system. After 25 min equipment stabilization in each room, the measurements were recorded during $10 \mathrm{~min}$. The data for each room was obtained using the software DeltaLog10 version 1.30. According to ISO 7730:2005 (International Organisation for Standardisation, 2005) and confirmed by observation, elderly occupants' daily activity was considered to have a metabolic rate of 1.0 met (seated, relaxed) and their clothing a thermal insulation of $1 \mathrm{clo}$ (underwear with short sleeves and legs, shirt, trousers, jacket, socks and shoes) in summer, and 1.3 clo (underwear with long sleeves, long trousers, long shirt, jersey, thermo-jacket, socks and shoes) in winter. PMV and PPD indices, mean radiant temperature (tr) and their measurement uncertainties were calculated by Monte Carlo Method using MatLab software.

\subsection{Calculation \& data analysis}

The IAQ and TC assessment results were compared to international reference levels, since the national reference levels are currently being updated to reflect recent changes. To characterize and rate the overall IAQ of the ECCs included in this study, the concentration of chemical and biological parameters was ranked from 1 to 3 . The ' 1 ' score was attributed when the mean concentration of each parameter in all ECCs was under the lower value within national (Ordinance 353-A/2013 of 4th December, 2013) and international references (see Table 2), the score ' 2 ' when the concentration levels were between the national and the international references, the score ' 3 ' when concentration values were higher than both reference levels and an intervention is required. For the purpose of this classification all chemical and biological parameters were considered to have the same influence on the IAQ. Classical statistical methods were used to estimate means, medians and frequencies (percentages) in order to obtain insight into the ECCs characteristics and environmental monitoring results within and between buildings. The variables were tested for normality with Shapiro-Wilk test and generally revealed a non-normal distribution, except for air temperature. Nonetheless it was decided to use the mean for descriptive purposes. Mann-Whitney $(U)$ test and Kruskal-Wallis $(H)$ for independent samples were conducted for seasonal effects assessment, indoor/outdoor and within buildings location differences. It was also performed a student $t$-test for the variable 'air temperature'. A 0.05 level of significance was used for all analyses. Expanded uncertainty was evaluated for $95 \%$ confidence interval based on probability distributions propagation of measurements obtained by multiple samples and considering instrumental uncertainty obtained from traceable calibrations. All data were analyzed using IBM SPSS 21.0.

\section{Results}

\subsection{Buildings characteristics}

The 22 ECCs are located in the urban area of Porto city, most of them $(n=17)$ in heavy traffic areas. A total of 716 elderly lived in these centers with a range of 7-136 occupants per building (generally 
three-storey houses with a little garden in front or in the back of the household). As regards construction characteristic, 53\% of ECCs are separate from surrounding buildings, $66 \%$ are an adaptation to ECC of an existing residential building, and 40\% ECCs are also developing activities of day care centers for elderly in separate facilities (due to technical and logistic reasons from the centers and to promote an effective and better service to those diverse care giving realities). The mean age of ECCs buildings is 111 years, ranging from 8 to 313 years. Retrofit average is 7 years.

Table 1 presents the main buildings characteristics. Most of them are built in stone masonry construction (49\%) with single pane windows (87\%). Only $30 \%$ have roof and walls insulation, while $61 \%$ of the sampled presented condensations and infiltrations along walls and roofs inside the buildings. The ceramic tile is the common roof lining (87\%) and the indoor floor is typically (48\%) covered by Vinyl (PVC). Twelve buildings (53\%) have central heating while the others have autonomous devices (one ECC had both installations), equally fueled with electricity or gas (39\%). All ECCs were smoke-free. Regarding the ventilation type, $87 \%$ had mixed ventilation (natural ventilation in the rooms along with exhaustion systems in the kitchen and bathrooms) while $13 \%$ had only natural ventilation in all the indoor areas.

\subsection{Environmental assessment}

During monitoring, the mean daily ambient air temperature in Porto was $17^{\circ} \mathrm{C}\left[11-23^{\circ} \mathrm{C}\right]$, with $49 \%$ [18-80\%] RH in the winter, and $24^{\circ} \mathrm{C}\left[17-34{ }^{\circ} \mathrm{C}\right]$ with $47 \%$ [18-76\%] RH in the summer. Table 2 shows the overall ECC indoor air quality analysis. $\mathrm{PM}_{2.5}$ mean concentration of the $22 \mathrm{ECC}$ was above the reference levels in both seasons. The other chemical and biological parameters concentration are within the reference levels. However there are maximum levels regarding $\mathrm{PM}_{10}, \mathrm{TVOC}, \mathrm{CO}_{2}$, bacteria and fungi that exceed the reference levels and might compromise the indoor air comfort. Formaldehyde samples also show a winter maximum level 3.2 times above the reference, but this might have happened during bricolage activities with the windows closed since the majority of the furniture in the ECCs is antique. Table 2 also reports significantly higher levels of TVOC, bacteria, $\mathrm{CO}$ and $\mathrm{CO}_{2}$ when compared to outdoors, in both seasons. Indoor $\mathrm{PM}_{10}$, TVOC, bacteria and $\mathrm{CO}_{2}$ show significant differences between seasons. Furthermore, $4 \%$ of fungi samples were positive for Aspergillus flavus ( $52 \%$ in summer) that often infect patients with reduced or compromised immune systems, Aspergillus

Table 1

Distribution of ECCs by building characteristics.

\begin{tabular}{lll}
\hline Building characteristics & $n$ & $\%$ \\
\hline ADAPTED To ECC & 14 & 66 \\
WALLS & 6 & 30 \\
$\quad$ Brickwork & 11 & 49 \\
Stone masonry & 5 & 22 \\
Both & 6 & 30 \\
WITH Roof \& Walls INSULATION & & \\
VENTILATION TYPE & 3 & 87 \\
Natural (only) & 19 & \\
Mixed ventilation & & 53 \\
HEATING & 12 & 43 \\
Central heating (CH) & 9 & 4 \\
Autonomous devices (AD) & 1 & \\
CH + AD & & 43 \\
WINDOWS & 13 & 13 \\
With sealants & 3 & 61 \\
Double-pane glass & 19 & 39 \\
Single-pane glass & & \\
BUILDING PATHOLOGIES & 13 & \\
Condensations + infiltrations & 9 & \\
Clear & &
\end{tabular}


Table 2

Elderly care centers indoor/outdoor air quality and thermal comfort: descriptive statistics by season.

\begin{tabular}{|c|c|c|c|c|c|c|}
\hline & \multicolumn{2}{|c|}{ Indoor } & \multicolumn{2}{|c|}{ Outdoor } & \multirow[t]{2}{*}{ Reference } & \multirow[t]{2}{*}{$p$} \\
\hline & $N$ & Mean [Min-Max] & $N$ & Mean [Min-Max] & & \\
\hline \multicolumn{7}{|l|}{$\mathrm{PM}_{10}\left(\mathrm{mg} / \mathrm{m}^{3}\right)$} \\
\hline SUMMER & 139 & $0.066[0,02-1.73]$ & 24 & $0.05[0.02-0.25]$ & $0.15^{\mathrm{a}}$ & $0.01^{*}$ \\
\hline WINTER & 138 & $0.067[0.02-0.43]$ & 24 & $0.06[0.02-0.21]$ & & \\
\hline \multicolumn{7}{|l|}{$\mathrm{PM}_{2.5}\left(\mathrm{mg} / \mathrm{m}^{3}\right)$} \\
\hline SUMMER & 120 & $0.09[0.02-2.12]$ & 20 & $0.05[0.02-0.18]$ & $0.035^{\mathrm{a}}$ & - \\
\hline WINTER & 119 & $0.06[0,02-0.86]$ & 20 & $0.05[0.02-0.29]$ & & \\
\hline \multicolumn{7}{|l|}{ TVOC (mg/m³) } \\
\hline SUMMER & 129 & $0.11[0.01-2.53]$ & 22 & $0.17[0.01-2,6]$ & $0.2^{\mathrm{b}}$ & $0.01^{*}$ \\
\hline WINTER & 137 & $0.13[0.01-0.93]$ & 20 & $0.04[0.01-0.3]$ & & $0.001^{* *}$ \\
\hline \multicolumn{7}{|c|}{ Formaldehyde $\left(\mathrm{mg} / \mathrm{m}^{3}\right)$} \\
\hline SUMMER & 77 & $<0.042[<0.042-0.06]$ & - & & $0.1^{\mathrm{c}}$ & - \\
\hline WINTER & 84 & $<0.042[<0.042-0.32]$ & & & & \\
\hline \multicolumn{7}{|l|}{$\mathrm{CO}\left(\mathrm{mg} / \mathrm{m}^{3}\right)$} \\
\hline SUMMER & 137 & $0.7[0.1-7.1]$ & 24 & $1.3[0.1-7.7]$ & $10^{\mathrm{c}}$ & $0.03^{* *}$ \\
\hline WINTER & 137 & $0.6[0.1-3.0]$ & 24 & $0.9[0.1-3.5]$ & & \\
\hline \multicolumn{7}{|l|}{$\mathrm{CO}_{2}\left(\mathrm{mg} / \mathrm{m}^{3}\right)$} \\
\hline SUMMER & 137 & 786 [538-2313] & 24 & 590 [384-893] & $1300^{d}$ & $0.001^{*}$ \\
\hline WINTER & 137 & 1125 [541-2697] & 24 & 609 [516-879] & & $0.001^{* *}$ \\
\hline \multicolumn{7}{|l|}{ Bacteria $\left(\mathrm{CFU} / \mathrm{m}^{3}\right)$} \\
\hline SUMMER & 137 & 329 [6-2282] & 23 & $162[24-616]$ & $500^{\mathrm{e}}$ & $0.01^{*}$ \\
\hline WINTER & 133 & 258 [14-996] & 23 & $89[8-368]$ & & $0.001^{* *}$ \\
\hline \multicolumn{7}{|l|}{ Fungi (CFU/m³) } \\
\hline SUMMER & 132 & 305 [6-2224] & 23 & $531[20-3454]$ & $500^{f}$ & - \\
\hline WINTER & 130 & 260 [18-2812] & 22 & 208 [62-676] & & \\
\hline \multicolumn{7}{|l|}{ Air temperature $\left({ }^{\circ} \mathrm{C}\right)$} \\
\hline SUMMER & 137 & $23.5[14.0-32.0]$ & 24 & $24.8[17.0-34.0]$ & Summer $[22,8-26,1]$ & $0.001^{*}$ \\
\hline Winter & 137 & $19.7[13.0-27.0]$ & 24 & $17.2[11-23.0]$ & Winter $[20,0-23,6]^{\mathrm{g}}$ & \\
\hline \multicolumn{7}{|l|}{ Relative humidity (\%) } \\
\hline SUMMER & 137 & $52.8[21.0-75.0]$ & 24 & $47.4[18-76]$ & {$[30-65]^{\mathrm{h}}$} & - \\
\hline WINTER & 137 & $49.7[24.0-75.0]$ & 24 & $49.0[18-80]$ & & \\
\hline \multicolumn{7}{|l|}{ Air velocity $(\mathrm{m} / \mathrm{s})$} \\
\hline SUMMER & 71 & $0.07[0.01-0.75]$ & - & - & $<0.25^{\mathrm{h})}$ & - \\
\hline WINTER & 79 & $0.12[0.01-1.26]$ & & & & \\
\hline \multicolumn{7}{|l|}{ PMV } \\
\hline SUMMER & 71 & $-0.4[-3.0-2.3]$ & - & - & Class A $[-0.2 ; 0.2]^{\mathrm{i}}$ & \\
\hline WINTER & 65 & $-1.7[-3.0-(-0.3)]$ & & & Class B $[-0.5 ; 0.5]$ & $0.001^{*}$ \\
\hline & & & & & Class C $[-0.7 ; 0.7]$ & \\
\hline \multicolumn{7}{|l|}{ PPD (\%) } \\
\hline SUMMER & 71 & $27.3[5.0-99.1]$ & - & - & Class $A<6^{\mathrm{i})}$ & \\
\hline WINTER & 65 & $58.9[6.8-99.2]$ & & & Class $\mathrm{B}<10$ & $0.001^{*}$ \\
\hline & & & & & Class $C<15$ & \\
\hline
\end{tabular}

a Environmental Protection Agency (2012).

b European Collaborative Action (1997).

c World Health Organization (2010)

d Finnish Society of Indoor Air Quality in 'The Thade Report' (2004).

e Decree-Law No. 79/2006 of April 4th, Annex VII.

${ }^{f}$ World Health Organization (2009).

g ASHRAE 55.

h IAQA 01-2003.

i ISO 7730:2005.

* Significant differences in indoor measurements by season (summer/winter).

** Significant differences by indoor/outdoor (overall measurements). 
fumigatus (32\% in summer; $19 \%$ in winter) that can cause invasive lung infections in susceptible individuals and Aspergillus niger (2\% in summer; $59 \%$ in winter) with toxigenic properties which some strains have been reported to produce mycotoxins and if large amounts of spores are inhaled cause aspergillosis. However the most predominant fungi species were Cladosporium and Penicillium species (Fig. 1), which are common in indoor and outdoor environments in all seasons.

A breakdown of IAQ and TC parameters by room and season is presented in Table 3. All the concentrations are within the reference levels except $\mathrm{PM}_{2.5}$. Higher levels of this parameter were found in all indoor samples collected, with a peak in the drawing rooms. $\mathrm{CO}_{2}$, bacteria and fungi presented the highest mean levels in the rooms with the highest occupancy rate, i.e., dining room and drawing room. There are significant differences between rooms and season for the following chemical and biological indoor air parameters, TVOC, bacteria and $\mathrm{CO}_{2}(p<0.01)$.

A distribution of all ECCs according to the overall quality rating described in the methods is reported in Fig. 2. The 14\% of the studied ECCs have a 'Good' IAQ with all the values under the national and international reference levels. All the other ECCs are classified as 'Acceptable' IAQ, and no center requires immediate intervention.

As regards TC parameters there are significant differences between season of air temperature, PMV, and PPD indices $(p=0.001)$, as shown in Table 2. PMV and PPD indices were measured and calculated only indoors, while air temperature was measured both indoors and outdoors. The lack of significant difference between indoor and outdoor measurements suggests a lack of insulation (Table 1).

The winter season PMV index for all ECCs shows results in the 'slightly cool' [ $\leqslant-1]$ thermal sensation scale [ -3 to 3], condition that may increase the risk of respiratory tract infections. The winter PMV (-1.7) and PPD (58.9\%) overall means are clearly out of the interval reference level showing discomfort in all the areas evaluated. Similarly, minimum winter and summer indoor air temperatures are out of the comfort levels (Table 2). Analyzing the TC parameters by room and season (Table 3) it is clear that in all the areas investigated the PMV winter index is below references and between the 'slightly cool' and 'cool' (-2) points in the thermal sensation scale (Fig. 3). Summer PMV indices indicates the bedrooms as the area closer to the 'slightly cool' point. The PPD indices, are not within references in any monitored room both in winter and summer season. The highest dissatisfaction is presented by the winter PPD index in the dining rooms probably because is a temporary place to stay and the heating system is not privileged in this area. The medical office is the area showing the

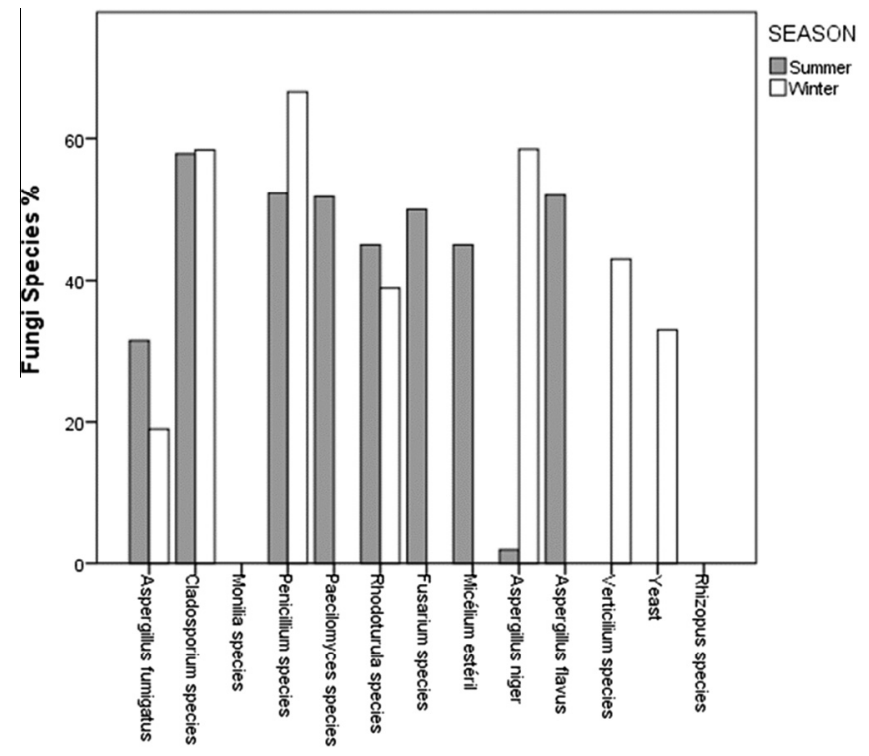

Fig. 1. ECCs indoor fungi species (mean percentage of the main identified species) by season. 
Table 3

Indoor air quality and thermal comfort parameters: descriptive statistics by room \& season [Kruskal-Wallis $(H)$ Test]

\begin{tabular}{|c|c|c|c|c|c|}
\hline & \multicolumn{5}{|l|}{ Mean [Min-Max] } \\
\hline & $\begin{array}{l}\text { Dining } \\
\text { Room }\end{array}$ & $\begin{array}{l}\text { Drawing } \\
\text { Room }\end{array}$ & Bedroom & Bedridden & Medical office \\
\hline \multicolumn{6}{|l|}{$\mathrm{PM}_{10}\left(\mathrm{mg} / \mathrm{m}^{3}\right)$} \\
\hline SUMMER & $0.14[0.02-1.7]$ & $0.06[0.02-0.32]$ & $0.05[0.02-0.35]$ & $0.05[0.02-0.17]$ & $0.03[0.02-0.05]$ \\
\hline WINTER & $0.07[0.02-0.3]$ & $0.07[0.02-0.43]$ & $0.07[0.02-0.37]$ & $0.05[0.02-0.2]$ & $0.05[0.02-0.09]$ \\
\hline \multicolumn{6}{|l|}{$\mathrm{PM}_{2.5}\left(\mathrm{mg} / \mathrm{m}^{3}\right)$} \\
\hline SUMMER & $0.06[0.02-0.3]$ & $0.11[0.02-1.39]$ & $0.05[0.02-0.26]$ & $0.2[0.02-2.1]$ & $0.3[0.02-0.6]$ \\
\hline WINTER & $0.06[0.02-0.2]$ & $0.08[0.02-0.6]$ & $0.06[0.02-0.9]$ & $0.03[0.02-0.11]$ & $0.04[0.02-0.13]$ \\
\hline \multicolumn{6}{|l|}{ TVOC $\left(\mathrm{mg} / \mathrm{m}^{3}\right)^{*}$} \\
\hline SUMMER & $0.1[0.03-0.7]$ & $0.13[0.01-2.5]$ & $0.12[0.02-0.9]$ & $0.04[0.02-0.08]$ & $0.06[0.03-0.15]$ \\
\hline WINTER & $0.14[0.01-0.7]$ & $0.15[0.03-0.9]$ & $0.13[0.02-0.8]$ & $0.09[0.03-0.3]$ & $0.15[0.02-0.2]$ \\
\hline \multicolumn{6}{|l|}{ Formaldehyde $\left(\mathrm{mg} / \mathrm{m}^{3}\right)$} \\
\hline SUMMER & $<0.042$ & $<0.042[<0.042-0.06]$ & $<0.042$ & $<0.042[<0.042-0.03]$ & $<0.042$ \\
\hline WINTER & $<0.042$ & $<0.042[<0.042-0.32]$ & $<0.042[<0.042-0.3]$ & $<0.042$ & $<0.042$ \\
\hline \multicolumn{6}{|l|}{$\mathrm{CO}\left(\mathrm{mg} / \mathrm{m}^{3}\right)$} \\
\hline SUMMER & $0.7[0.1-4.4]$ & $0.6[0.1-5.4]$ & $0.8[0.1-7.1]$ & $0.9[0.1-5.3]$ & $0.5[0.1-1.2]$ \\
\hline WINTER & $0.6[0.1-2.3]$ & $0.6[0.1-2.6]$ & $0.7[0.1-3.0]$ & $0.47[0.1-1.9]$ & $0.3[0.1-0.8]$ \\
\hline \multicolumn{6}{|l|}{$\mathrm{CO}_{2}\left(\mathrm{mg} / \mathrm{m}^{3}\right)^{*}$} \\
\hline SUMMER & 938 [595-2313] & 833 [553-1583] & 728 [538-1221] & 689 [543-984] & $718[640-842]$ \\
\hline WINTER & 1323 [563-2374] & 1157 [541-2009] & 1001 [579-2697] & 1143 [678-1590] & 1243 [581-2113] \\
\hline \multicolumn{6}{|l|}{ Bacteria $\left(\mathrm{CFU} / \mathrm{m}^{3}\right)^{*}$} \\
\hline SUMMER & $427[92-1414]$ & $411[36-2282]$ & $252[6-1386]$ & $269[58-1052]$ & $342[84-650]$ \\
\hline WINTER & 298 [14-996] & $293[44-838]$ & 210 [20-630] & $262[40-618]$ & $343[30-820]$ \\
\hline \multicolumn{6}{|l|}{ Fungi (CFU/m³ $\left.{ }^{3}\right)$} \\
\hline SUMMER & $412[8-2224]$ & 269 [38-1010] & $290[6-1128]$ & 251 [34-640] & $387[36-824]$ \\
\hline WINTER & 366 [38-2812] & $259[26-784]$ & $241[18-1218]$ & $218[18-502]$ & $171[80-284]$ \\
\hline \multicolumn{6}{|l|}{ Air Temperature $\left({ }^{\circ} \mathrm{C}\right)^{*}$} \\
\hline SUMMER & $24.0[17.0-31.0]$ & $23.6[16.0-32.0]$ & $23.2[14.0-32.0]$ & $23.6[20.0-27.0]$ & $24.2[21.0-27.0]$ \\
\hline WINTER & $20.0[15.0-24.0]$ & $19.5[16.0-24.0]$ & $19.5[13.0-27.0]$ & $20.6[16.0-24.0]$ & $20.3[15.0-23.0]$ \\
\hline \multicolumn{6}{|l|}{ Relative humidity (\%) } \\
\hline SUMMER & $53.1[23.0-72.0]$ & $52.9[28.0-72.0]$ & $53.3[28.0-75.0]$ & $54.9[32.0-67.0]$ & $41.3[21.0-59.0]$ \\
\hline WINTER & $50.8[31.0-75.0]$ & $49.8[25.0-68.0]$ & $49.2[24.0-72.0]$ & $51.2[28.0-73.0]$ & $46.3[32.0-58.0]$ \\
\hline
\end{tabular}




\begin{tabular}{|c|c|c|c|c|c|}
\hline \multicolumn{6}{|l|}{ Air Velocity $(\mathrm{m} / \mathrm{s}$ ) } \\
\hline SUMMER & $0.05[0.01-0.11]$ & $0.11[0.01-0.8]$ & $0.06[0.01-0.48]$ & $0.04[0.01-0.2]$ & $0.1[0.1]$ \\
\hline WINTER & $0.09[0.01-0.5]$ & $0.15[0.01-1.17]$ & $0.08[0.01-0.89]$ & $0.23[0.01-1.26]$ & $0.05[0.01-0.13]$ \\
\hline \multicolumn{6}{|l|}{$\mathrm{PMV}^{*}$} \\
\hline SUMMER & $-0.06[(-2.5)-0.9]$ & $-0.3[(-2.5)-2.3]$ & $-0.7[(-3.0)-2.0]$ & $-0.2[(-1.3)-0.8]$ & $0.4[0.2-0.6]$ \\
\hline WINTER & $-1.9[(-2.8)-(-1.0)]$ & $-1.7[(-2.9)-(-0.3)]$ & $-1.7[(-3.0)-(-0.3)]$ & $-1.6[(-2.5]-(-0.8)]$ & $-1.3[(-1.7)-(-1.0)]$ \\
\hline \multicolumn{6}{|l|}{ PPD (\%) ${ }^{*}$} \\
\hline SUMMER & $23.1[5.1-93.8]$ & $26.3[5.2-93.2]$ & 33.9 [5.0-99.1] & $17.3[5.2-41.4]$ & $8.8[5.6-11.9]$ \\
\hline WINTER & $69.5[26.7-98.0]$ & 59.8 [7.4-98.6] & 58.9 [6.8-99.2] & $57.6[17.8-92.9]$ & $38.0[26.4-60.6]$ \\
\hline
\end{tabular}

* Significant differences by room and season (summer/winter) $p<0.01$. 


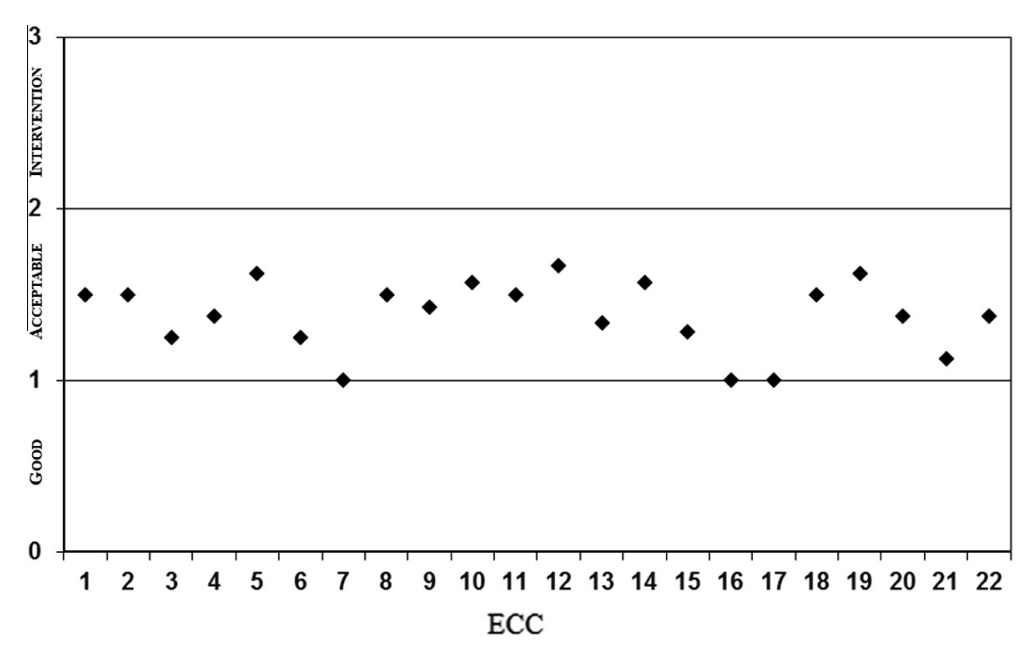

Fig. 2. Overall rating of ECCs indoor air quality.
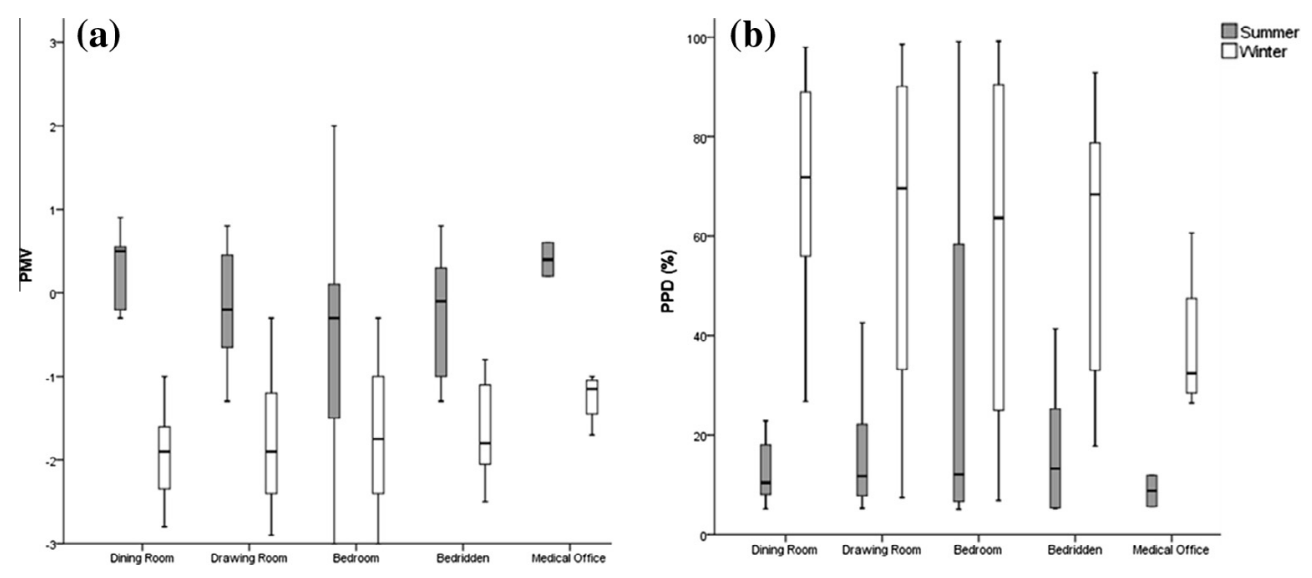

Fig. 3. (a) PMV index by room and season, (b) PPD index (\%) by room and season (mean of the 22 ECCs).

minimal variability of PPD and PMV, both in winter and summer, suggesting a more accurate control of temperature. In general, PPD and PMV indices largely differ by room and by season $(p<0.01)$. These differences are clearly shown by Fig. 3a (PMV index) and Fig. 3b (PPD index).

\subsection{Building characteristics vs. environmental assessment}

This section explore the possible influence of building characteristics on the indoor environmental quality. A summary view of the association between these variables is reported in Table 4 . The building characteristics 'Insulation', 'Heating Ventilation' and 'Windows frames' appear to be the most influential parameters on IAQ and TC. The environmental parameters most commonly affected by building characteristics are the 'Bacteria', 'Fungi', 'Temperature', Relative Humidity', and 'PPD index'.

Regarding the indoor air suspended particles, $\mathrm{PM}_{10}$ presents significant differences depending on windows characteristics, whereas $\mathrm{PM}_{2.5}$ is also affected by ventilation characteristics, type of roof lining and insulation, and by the presence of architectural modification to adapt the building to the use as 
Table 4

Building characteristics in the indoor environmental evaluation.

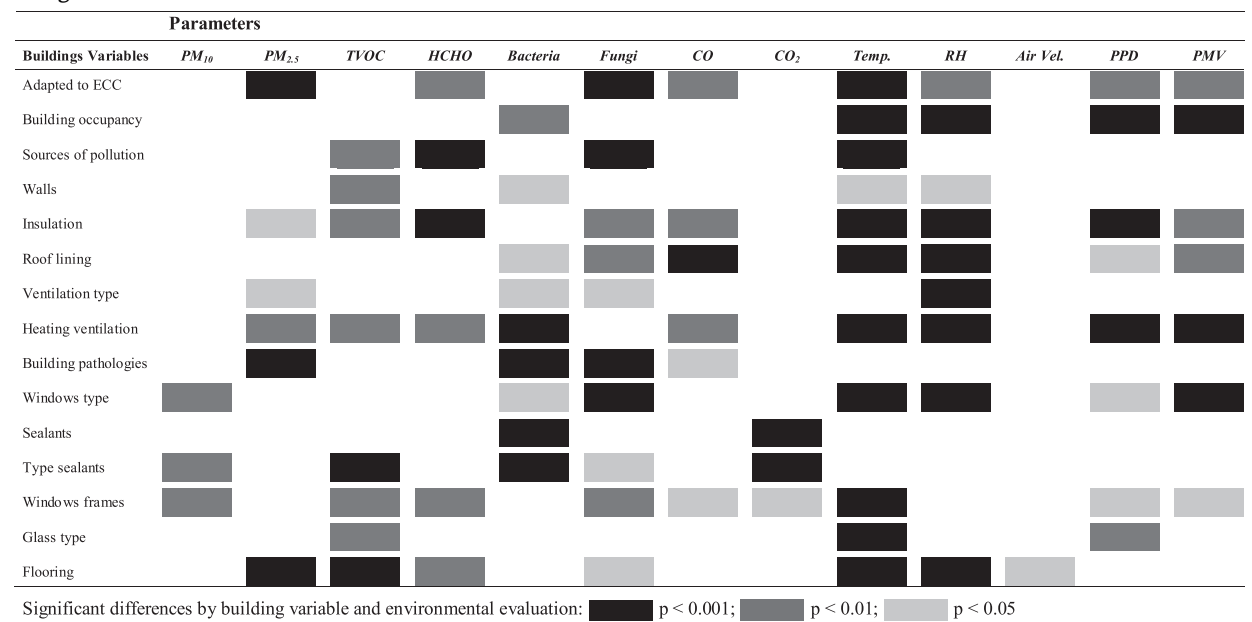

ECC ('adapted to ECC'). TVOC is higher if the building is close to sources of pollution, and depends also by building insulation, ventilation characteristics, windows, walls and floor characteristics. Formaldehyde is significantly affected by the condition of 'adapted to ECC', by 'insulation' and type of flooring. Similarly, $\mathrm{CO}$ is higher in building 'adapted to ECC' and is modified by insulation and roof lining characteristics. $\mathrm{CO}_{2}$ shows differences also depending upon the presence of windows sealants and the type of these sealants. The presence of bacteria depends on heating/ventilation or the presence of building pathologies. Fungi concentrations is associated to 'adapted to ECC', 'sources of pollution', 'insulation', roof and windows characteristics, and building pathologies such as infiltrations and condensations.

Concerning the TC, temperature is modified by essentially all building characteristics except by the type of ventilation, the building pathologies, and the windows sealant characteristics. $\mathrm{RH}$ varies according to the building purpose and occupancy, the insulation and ventilation characteristics, and roof, walls, floor and windows features. These findings are overlapping those of PMV and PPD indices, with the exception of the glass-type variable for PPD.

\section{Discussion}

Aging is associated with a decline in immune defense and respiratory function, and predisposition to respiratory infections (Boita et al., 2006). Due to these conditions, elderly are more susceptible to the effects of air pollution, and since they spend the large majority of their time indoors, monitoring IAQ and TC in elderly centers is a public health priority (Bentayeb et al., 2013). With this purpose the GERIA project aims to characterize the ECC indoor environment and explore the influence of building characteristics on IAQ parameters. Our study found higher levels of $\mathrm{PM}_{2.5}$ in all ECC spaces in both seasons, compared to the international reference levels, revealing that particle matter concentrations is a critical parameter of air quality, both for its sensitivity and for its possible influence on human health. The findings which showed as this parameter is strongly depending to season, filter usage, relative humidity, air exchange ratios, number of occupants, outdoor PM levels, sweeping/dusting, and presence of a central air conditioner, reported a number of critical issue for any programs aimed at preventing exposure to inhalable toxic agents of the elderly population (Batterman et al., 2012).

Our mean overall indoor $\mathrm{PM}_{2.5}$ evaluations were about 3 times above the US EPA (Environmental Protection Agency, 2012) reference levels, with the highest values in the bedridden subset and medical office. This might be due to combination of outdoor contamination, occupancy rate and the accelerated particle resuspension in spaces dedicated to indoor activities (Hospodsky et al., 2012). Other 
studies (Wang et al., 2006; Bentayeb et al., 2013) have found, high levels of $\mathrm{PM}_{2.5}$ in similar indoor environments, and the link with lung function (Lee et al., 2007) and respiratory diseases such as COPD (Osman et al., 2007; Liu et al., 2007) has been quite demonstrated. Weather generated by indoor or outdoor pollution the $\mathrm{PM}_{2.5}$ is acknowledged by WHO and by EPA as a known cause health risk for lung and heart diseases (including asthma) (World Health Organization, 2006).

Although all the other indoor air pollutants were within the reference levels peak values of $\mathrm{PM}_{10}$, TVOC, $\mathrm{CO}_{2}$, bacteria and fungi exceeded the reference levels, compromising indoor air comfort and worsening the already existent respiratory chronic diseases. A VOC study in the elderly French dwellings show statistically significant associations between breathlessness and living in dwellings with elevated concentrations of toluene and o-xylene in elderly population (Bentayeb et al., 2013).

When TVOC, bacteria, $\mathrm{CO}$ and $\mathrm{CO}_{2}$ indoor levels are compared with ambient air they were higher in both seasons, suggesting as indoor pollution is the most important source of exposure, at least in this population. Indoor ECCs activities influence pollution levels, especially in the winter season. Seasonality is a critical parameter affecting the level of exposure to $\mathrm{PM}_{10}$, TVOC, bacteria and $\mathrm{CO}_{2}$, and simple behaviors such as opening and closing windows may dramatically change these values. Dining rooms and drawing rooms are expected to have the highest mean and maximum levels of $\mathrm{PM}_{10}, \mathrm{CO}_{2}$ and bacteria concentration due to higher occupancy rate in these room areas when compared to bedrooms and medical offices. An inadequate ventilation can increase exposure not bringing in enough outdoor air to dilute emissions from indoor sources and allowing indoor air pollutants out of the rooms (Annesi-Maesano et al., 2013). Similar conditions may explain significant differences between rooms and season for TVOC, bacteria and $\mathrm{CO}_{2}$.

Although the most predominant airborne fungi species found in the ECCs were Cladosporium and Penicillium species, which are common in indoor and outdoor environments, we also found samples positive for the genotoxic and pathogenic species of Aspergillus. These species may infect patients with reduce or compromised immune systems and may cause invasive lung infections in susceptible individuals such as elderly. The lack of building insulation causes ECC rooms to have similar temperature and humidity of outdoors, while the high rate of building pathology, e.g., condensations and infiltrations, may influence positive results, since the environmental parameter 'Fungi' was strictly associated to the building characteristics 'Insulation' and 'Building pathologies' (Sandstrom and Viegi, 2003; Hulin et al., 2012). Temperature and humidity levels can also increase the concentration of some pollutants.

In an overall perspective this study shows reassuring results about IAQ in the ECCs evaluated. More than $1 / 3$ of the studied ECCs reported excellent results, regarding the control of chemical and biological pollutants. However, although no ECC requires immediate intervention according to international and national reference levels, these thresholds may not be appropriate for susceptible populations, and specifically for elderly, which besides the increased biological sensitivity to the effect of air pollution spend nearly the $100 \%$ of their time in indoor spaces. Dedicated exposure/effect models should be developed for this population (United States Environmental Protection Agency (US EPA), 2011).

Thermal environmental comfort is another major issue for the elderly population (Raymann and Van Someren, 2008). Several studies demonstrated the effect of ambient temperature on cardio-respiratory mortality (Halonen et al., 2010) and these findings were replicated with indoor climate (Bokenes et al., 2011). In general, elderly perceive TC differently from the young due to a combination of physical ageing and behavioral differences (Hoof and Hensen, 2006; van Hoof, 2008). Studies show that older adults prefer a warmer environment $\left(+2^{\circ} \mathrm{C}\right)$ than younger people (Hoof and Hensen, 2006). The standard $20-24{ }^{\circ} \mathrm{C}$ comfort zone may be not warm enough for older adults, which reported an optimum temperature above $25^{\circ} \mathrm{C}$ for sedentary older adults (Hwang and Chen, 2010). The TC results or our study showed significant differences between room and season for air temperature, especially for PMV and PPD indices, suggesting that the building and heating characteristics may affect indoor variance in the winter/summer temperature and RH. Moreover, thermal comfort depends also by individual parameters such as the degree of activity, the clothing worn by the individual, the age, health status, gender, and the adaptation to the local environment and household. Other factors like rooms crowding or under-occupancy may have an influence, and so is for the variability during the day and over time (Ormandy and Ezratty, 2012). However, the results of the winter season PMV index in our study show that thermal sensation scale in all analyzed rooms ranged between the 'slightly 
cool' $(-1)$ and 'cool' $(-2)$, while minimum winter and summer indoor air temperatures were constantly out of the comfort levels. Colder environments may potentiate elderly respiratory tract infections and also increase hospital consultations (Hajat et al., 2004). Among the other results also the inflammation caused by respiratory syncytial virus may be modified by the biologically active contaminants of indoor air (Foster et al., 2003). The prevalence in our study group of buildings built in stone masonry with poor insulation and a limited availability of double-pane glass may explain this low thermal sensation scale index (PMV) and the high percentage of PPD (59\%) index in the winter season, and pave the way for the most urgent structural interventions. To be noted that the presence of diverse heating systems in the ECCs evaluated did not significantly affect average indoor temperature in the winter season $\left(19.7^{\circ} \mathrm{C}\right)$, which constantly stay below reference values for neutral/comfort temperature.

The present study investigated a large selection of indoor air pollutants and TC parameters in ECCs both in summer and winter season. Several significant differences were found for IAQ and TC parameters when compared by season, when indoor parameters were compared with outdoor, when differences between the 22 ECCs or their internal spaces were tested. Although the reliability of $p$ values associated to hypothesis testing is limited - as in this case - by the presence of multiple comparison, these data provide a comprehensive view on the quality of IAQ and TC in this setting, and especially on the relative importance of building characteristics and ECCs daily life activities in determining indoor conditions in the ECCs. Our findings which are in keeping with our project preliminary results (Mendes et al., 2013), provide remarkable information to assess housing structure and function along with lifestyle decisions determinants to IAQ. This research will contribute to the understanding of the health effects due to IAQ variables and their potential to improve the health of our elderly population.

In conclusion, these results provided critical data on how maintaining comfortable indoor temperatures and good IAQ for susceptible populations living in ECCs, suggesting a high priority to intervention regarding insulation devices, such as, roof, walls and windows insulation.

\section{Conclusions}

Indoor environmental health risks may depend in complex and subtle ways on factors such as the time pattern of exposure, as well as on host factors like age, gender, genetic heritage, and underlying state of health. Our study focused on the assessment of indoor environmental variables (IAQ and TC) in the ECCs that might influence elderly comfort and wellbeing and interact with their already existent chronic diseases. Our study suggested that the IAQ in the ECCs of the Porto area is acceptable and no immediate intervention is required. Attention is needed to peak concentrations and fungi species that might compromise IAQ comfort. The concentration reduction of indoor air pollutants, in particular, particle matter and its health effects range from regulatory measures (stricter air quality standards, limits for emissions from various sources), structural changes (such as reducing energy consumption, especially that based on combustion sources, changing modes of transport, land use planning) as well as behavioral changes by individuals by, for example, using cleaner modes of transport or household energy sources. Nevertheless, adequate measures, such as, local exhaust ventilation systems near cooking and gas burning devices, as well as, daily slightly moist cleaning of the rooms surfaces would reduce particle accumulation and re-suspension. To prevent low indoor temperatures and discomfort, especially on winter season, simple measures could provide health benefits to ECC residents and workers, such as insulating ceilings, walls, and windows, maintaining natural and passive ventilation, solutions that are common in Portugal due to the advantage of the country's generally mild weather. More studies on indoor pollutants and health in the elderly are needed, with focus on exposure assessment, providing a better understanding of the adverse health effects induced by indoor air pollution in elderly.

\section{Acknowledgments}

We are indebted to all of the participants in the GERIA Project as well as to the professionals and elderly residents in the ECCs and the authorities from which they depend. Our current research is 
supported by GERIA Project (www.geria.webnode.com): PTDC/SAU-SAP/116563/2010 and a PhD Grant (SFRH/BD/72399/2010) from Foundation for Science and Technology (Fundação para a Ciência e Tecnologia - FCT). SB and RM work was supported by a grant funded by AIRC (Associazione Italiana per la Ricerca sul Cancro).

\section{References}

Annesi-Maesano, I. et al, 2013. Geriatric study in Europe on health effects of air quality in nursing homes (GERIE study) profile: objectives, study protocol and descriptive data. Multidisciplinary Respir. Med. 8, 71.

Antunes, H.K.M. et al, 2005. Analysis of resting metabolic rate and body composition in elderly males before and after six months of endurance exercise. Rev. Bras. Med. Esporte 11 (1), 76-80.

Batterman, S. et al, 2012. Particulate matter concentrations in residences: an intervention study evaluating stand-alone filters and air conditioners. Indoor Air 22 (3), 235-252.

Bentayeb, M. et al, 2013. Higher prevalence of breathlessness in elderly exposed to indoor aldehydes and VOCs in a representative sample of French dwellings. Respir. Med. 107 (10), 1598-1607.

Bentayeb, M. et al, 2013. Indoor air pollution and respiratory health in the elderly. J. Environ. Sci. Health, Part A: Toxic/Hazard. Subst. Environ. Eng. 48 (14), 1783-1789.

Boita, F. et al, 2006. Evaluation of pulmonary function in the elderly. Intergroupe Pneumo Geriatrie SPLF-SFGG. Rev. Mal. Respir. 23 (6), 619-628.

Bokenes, L. et al, 2011. Annual variations in indoor climate in the homes of elderly persons living in Dublin, Ireland and Tromso, Norway. Eur. J. Public Health 21 (4), 526-531.

Caley, M., Sidhu, K., 2011. Estimating the future healthcare costs of an aging population in the UK: expansion of morbidity and the need for preventative care. J. Public Health (Oxford) 33 (1), 117-122.

Corsi, R., Kinney, K., Levin, H., 2012. Microbiomes of built environments: 2011 symposium highlights and work-group recommendations. Indoor Air 22, 171-172.

Damiani, G. et al, 2009. An ecological study on the relationship between supply of beds in long-term care institutions in Italy and potential care needs for the elderly. BMC Health Serv. Res. 9, 174.

Environmental Protection Agency, The National Ambient Air Quality Standards for Particle Pollution, in Revised Air Quality Standards for Particle Pollution and Updates to the Air Quality Index (AQI). 2012, Environmental Protection Agency.

European Commission Joint Research Centre Environment Institute, Total Volatile Organic Compounds (TVOC) in Indoor Air Quality Investigations, in Environment \&' Quality of Life, E.C. Action, Editor. 1997.

Foster, S. et al, 2003. Respiratory syncytial virus infection and virus-induced inflammation are modified by contaminants of indoor air. Immunology 108, 109-115.

Hajat, S., Bird, W., Haines, A., 2004. Cold weather and GP consultations for respiratory conditions by elderly people in 16 locations in the UK. Eur. J. Epidemiol. 19 (10), 959-968.

Halonen, J.I. et al, 2010. Associations between outdoor temperature and markers of inflammation: a cohort study. Environ. Health 9, 42.

Hoof, v.J., Hensen, J.L.M., 2006. Thermal comfort and older adults. Gerontechnology 4 (4), 223-228.

Hospodsky, D. et al, 2012. Human occupancy as a source of indoor airborne bacteria. PLoS ONE 7 (4).

Hulin, M. et al, 2012. Respiratory health and indoor air pollutants based on quantitative exposure assessments. Eur. Respir. J. 40 $1033-1045$.

Hwang, R.L., Chen, C.P., 2010. Field study on behaviors and adaptation of elderly people and their thermal comfort requirements in residential environments. Indoor Air 20 (3), 235-245.

International Organisation for Standardisation, ISO 7726:1998 - Ergonomics of the thermal environments. Instruments for measuring physical quantities. 1998

International Organisation for Standardisation, ISO 7730:2005 - Ergonomics of the thermal environment - Analytical determination and interpretation of thermal comfort using calculation of the PMV and PPD indices and local thermal comfort criteria. 2005.

International Organisation for Standardization, 2003. ISO 4833:2003 Microbiology of Food and Animal Feeding Stuffs Horizontal Method for the Enumeration of Microorganisms - Colony-count Technique at $30{ }^{\circ} \mathrm{C}$. International Organisation for Standardization.

International Organisation for Standardization, 2011. ISO 16000-18:2011: Indoor air - Part 18 - Detection and Enumeration of Moulds - Sampling by Impaction. International Organisation for Standardization.

International Organization for Standardization, 2004. International Standard ISO 16000-6 Indoor air - Part 6 Determination of Volatile Organic Compounds in Indoor and Test Chamber Air by Active Sampling on Tenax TA Sorbent, Thermal Desorption and Gas Chromatography Using MS/FID. International Organization for Standardization.

Kembel, S.W. et al, 2012. Architectural design influences the diversity and structure of the built environment microbiome. ISME J. 6 (8), 1469-1479.

Kovats, R.S., Hajat, S., 2008. Heat stress and public health: a critical review. Annu. Rev. Public Health 29, 41-55.

Lee, J.T., Son, J.Y., Cho, Y.S., 2007. The adverse effects of fine particle air pollution on respiratory function in the elderly. Sci. Total Environ. 385, 28-36.

Levin, J., Lindahl, R., Andersson, K., 1996. A passive sampler for formaldehyde in air using 2,4 dinitrophenylhydrazine-coated glass fiber filters. Environ. Sci. Technol. 20, 1273-1276.

Liu, S. et al, 2007. Biomass fuels are the probable risk factor for chronic obstructive pulmonary disease in rural South China. Thorax 62, 889-897.

Mendes, A. et al, 2013. Indoor air quality and thermal comfort-results of a pilot study in elderly care centers in Portugal. J. Toxicol. Environ. Health A 76 (4-5), 333-344.

Mourtzoukou, E.G., Falagas, M.E., 2007. Exposure to cold and respiratory tract infections. Int. J. Tuberc. Lung Dis. 11 (9), $938-$ 943. 
National Institute for Occupational Safety and Health (NIOSH), Bioaerosol Sampling (Indoor Air) 0800: culturable organisms bacteria, fungi, thermophilic actinomycetes, in Issue 1, 1998. NIOSH Manual of Analytical Methods (NMAM), fourth ed.

National Institute for Occupational Safety and Health, Formaldehyde 2016, in Issue 2, 2003. NIOSH Manual of Analytical Methods (NMAM), fourth ed.

Ordinance 353-A/2013 of 4th December. Diário da República, 1. a série, No. 235. Ministry of Environment, Territory Planning, Health and Solidarity, Employment and Social Security. 2013.

Ormandy, D., Ezratty, V., 2012. Health an thermal comfort: from WHO guidance to housing strategies. Energy Policy, Elsevier 49, $116-121$.

Osman, L.M. et al, 2007. Indoor air quality in homes of patients with chronic obstructive pulmonary disease. Am. J. Respir. Crit. Care Med. 176, 465-472.

Raymann, R., Van Someren, E., 2008. Diminished capability to recognize the optimal temperature for sleep initiation may contribute to poor sleep in elderly people. Sleep 31 (9).

Sandstrom, T., Viegi, G., 2003. Air pollution effects in the elderly. Eur. Respir. J. 21 (Suppl. 40), 1-96.

Schellen, L. et al, 2010. Differences between young adults and elderly in thermal comfort, productivity, and thermal physiology in response to a moderate temperature drift and a steady-state condition. Indoor Air 20 (4), 273-283.

Seppänen, O., et al., Performance criteria of buildings for health \& comfort: task group 42, in ISIAQ - SIB. 2004.

Simoni, M. et al, 2003. Indoor air pollution and respiratory health in the elderly. Eur. Respir. J. 21 (Supplement 40), 15S-20s. Sørensen, M. et al, 2003. Personal exposure to PM2 5 and biomarkers of DNA damage. Cancer Epidemiol. Biomark. Prev. 12.

Spengler, J., Adamkiewicz, G., 2009. Indoor air pollution: an old problem with new challenges. Int. J. Environ. Res. Public Health 6 (11), 2880-2882.

United States Environmental Protection Agency (US EPA), 2011. Data Sources Available for Modeling Environmental Exposures in Older Adults. Office of Research and Development - National Exposure Research Laboratory.

van Hoof, J., 2008. Forty years of Fanger's model of thermal comfort: comfort for all? Indoor Air 18 (3), $182-201$.

Wan, G.H., Chung, F.F., Tang, C.S., 2011. Long-term surveillance of air quality in medical center operating rooms. Am. J. Infect. Control 39 (4), 302-308.

Wang, X. et al, 2006. Hospital indoor PM10/PM2.5 and associated trace elements in Guangzhou, China. Sci. Total Environ. 366 (1), 124-135.

Winberry, W.T. et al, 1990. Method for Determination of Indoor Air Pollutants: EPA Methods. Noyes Data Corporation, New Jersey, pp. 670-753.

World Health Organization, WHO Air quality guidelines for particulate matter, ozone, nitrogen dioxide and sulfur dioxide - Global update 2005 - Summary of risk assessment. 2006, World Health Organization. 